\title{
Mechanistic study of the ring-size modulation in Michael-Dieckmann type reactions of 2-acylaminoacrylates with ketene diethyl acetal $\dagger \neq$
}

\author{
Alberto Avenoza, ${ }^{* a}$ Jesús H. Busto, ${ }^{a}$ Noelia Canal, ${ }^{a}$ José I. García, ${ }^{b}$ \\ Gonzalo Jiménez-Osés, ${ }^{a}$ Jesús M. Peregrina $^{a}$ and Marta Pérez-Fernández ${ }^{a}$
}

\author{
Received (in Montpellier, France) 19th October 2006, Accepted 23rd November 2006 \\ First published as an Advance Article on the web 19th December 2006 \\ DOI: $10.1039 / b 615220 a$
}

An unexpected modulation of the chemoselectivity in the Michael-Dieckmann type reactions of 2-acylaminoacrylates with ketene diethyl acetal is observed, depending on the nature of the acylamino group. Experimental and theoretical studies are presented to offer insights into the origin of this substituent effect in terms of a polar stepwise mechanism.

\section{Introduction}

The cyclobutane structure has been the object of great interest in recent years since it can be regarded as an excellent molecular building block for organic synthesis. ${ }^{1}$ Particular attention has been paid to the 1-amino-1-cyclobutanecarboxylic acid derivatives due to their biological significance as neurotransmitters. ${ }^{2}$ In this sense, a synthetic approach to 2-substituted cyclobutane amino acids has been developed recently in our research group., ${ }^{3,4}$ The route involves the thermal $[2+2]$ cycloaddition of ketene diethyl acetal (1), as the electron-rich olefin, with methyl 2-acetamidoacrylate (2a), as the electron-poor olefin (Scheme 1). It is well-documented ${ }^{3,5}$ that this kind of cycloaddition not only leads to cyclobutanes but, in certain cases, the zwitterionic intermediate $(\mathrm{ZW})$ can react with another olefin molecule to give cyclohexanes. We previously observed this behavior in the reaction of olefins 1 and $\mathbf{2 a}$ in the presence of Lewis acids (LA), which promote the formation of the cyclohexane derivative 4a. It is worth noting that the thermal reaction (in the absence of LA) leads exclusively to the cyclobutane product (compound 3a). ${ }^{3}$

\section{Results and discussion}

Previous studies on thermal [2 +2$]$ cycloadditions $^{3}$ of olefins $\mathbf{1}$ and $\mathbf{2 a}$ led us to consider replacing the acetamido group with a trifluoroacetamido group (olefin $\mathbf{2 b}$ ) to avoid the use of Lewis acids. We were pleased to observe that this simple change in substituent led to the exclusive formation of a cyclohexane product (the isolated product $\mathbf{5 b}$ was spontaneously formed

\footnotetext{
${ }^{a}$ Departamento de Quimica, Universidad de La Rioja, Grupo de Sintesis Quimica de La Rioja, U.A.-C.S.I.C., E-26006 Logroño,

Spain.E-mail: alberto.avenoza@dq.unirioja.es; Fax: + 34941299655

${ }^{b}$ Departamento de Química Orgánica, Instituto de Ciencia de

Materiales de Aragón, C.S.I.C.-Universidad de Zaragoza, E-50009

Zaragoza, Spain.E-mail: jig@unizar.es; Fax: + 34976762077

$\dagger$ The HTML version of this article has been enhanced with colour images.

$\ddagger$ Electronic supplementary information (ESI) available: NMR data for compound $\mathbf{5 b}$. Materials balance on reaction of olefins $\mathbf{1}$ and $\mathbf{2 b}$. Tables for energies, enthalpies, free energies, and entropies of the structures considered in this work in vacuum and solution. Cartesian coordinates for the different conformations of the structures considered in this work. See DOI: 10.1039/b615220a.
}

from $\mathbf{4 b}$ in the reaction medium) instead of the usual cyclobutane skeleton (Scheme 1). The reaction of olefin 1 and fluorinated $\mathbf{2 b}$ was carried out at different temperatures (from -20 to $83{ }^{\circ} \mathrm{C}$ ) in two solvents, tert-butyl alcohol and acetonitrile, and these reactions gave exclusively the cyclohexenone derivative 5b. The best yield obtained after purification by column chromatography was $22 \%$ (acetonitrile, $83{ }^{\circ} \mathrm{C}$ ). Apparently, this yield is low compared with that previously reported for the reaction of olefins $\mathbf{1}$ and $\mathbf{2 a}$ (tert-butyl alcohol, $83{ }^{\circ} \mathrm{C}, 64 \%$ ); nevertheless, it is important to notice that this new process corresponds to four steps. Moreover, we performed a materials balance study using NMR diffusion experiments (2D-DOSY) and gas chromatography, showing that the existence of competitive reactions with $\mathbf{2 b}$ can be, consequently, discarded (see ESI $\ddagger$ ). The structures of compounds $\mathbf{3 a}$ and $\mathbf{5 b}$ were unambiguously determined using X-ray diffraction. $^{3}$

To rationalize these observations, we decided to elucidate the complete mechanism of these reactions, in an effort to locate the true source of chemoselectivity. We evaluated firstly the concerted or stepwise character of these formal ketene acetal-acrylate $[2+2]$ reactions. In this sense, when the reaction of olefin $\mathbf{1}$ with $\mathbf{2 a}$ was carried out in various solvents of different polarity (further details are given in the ESI $\ddagger$ ), we observed that the yield of the cycloaddition increased with polar solvents, which is indicative of a polar reaction mechanism $^{6}$ involving 1,4-Zwitterionic tetramethylene intermediates $(\mathrm{ZW} 1)^{7}$ (Scheme 1). Additionally, the reversibility of the reaction was demonstrated by the observation of starting olefin 2a after heating cyclobutane $3 \mathbf{a}$ at $83{ }^{\circ} \mathrm{C}$ in tert-butyl alcohol for one day. Moreover, cyclobutane 3a was completely transformed into olefin $\mathbf{2 a}$ when it was injected into a gas chromatograph.

With this experimental background in mind, we carried out a thorough theoretical study of the possible reaction pathways between the aforementioned olefins. It is worth mentioning that, while the photochemical [2 +2$]$ cycloaddition has been extensively treated from a theoretical point of view, ${ }^{8}$ the thermal $[2+2]$ cycloaddition has not received the same level of attention, although some reviews concerning mechanistic considerations have been published. ${ }^{9}$ In this respect, several theoretical studies on $[2+2]$ cycloadditions involving ketenes 


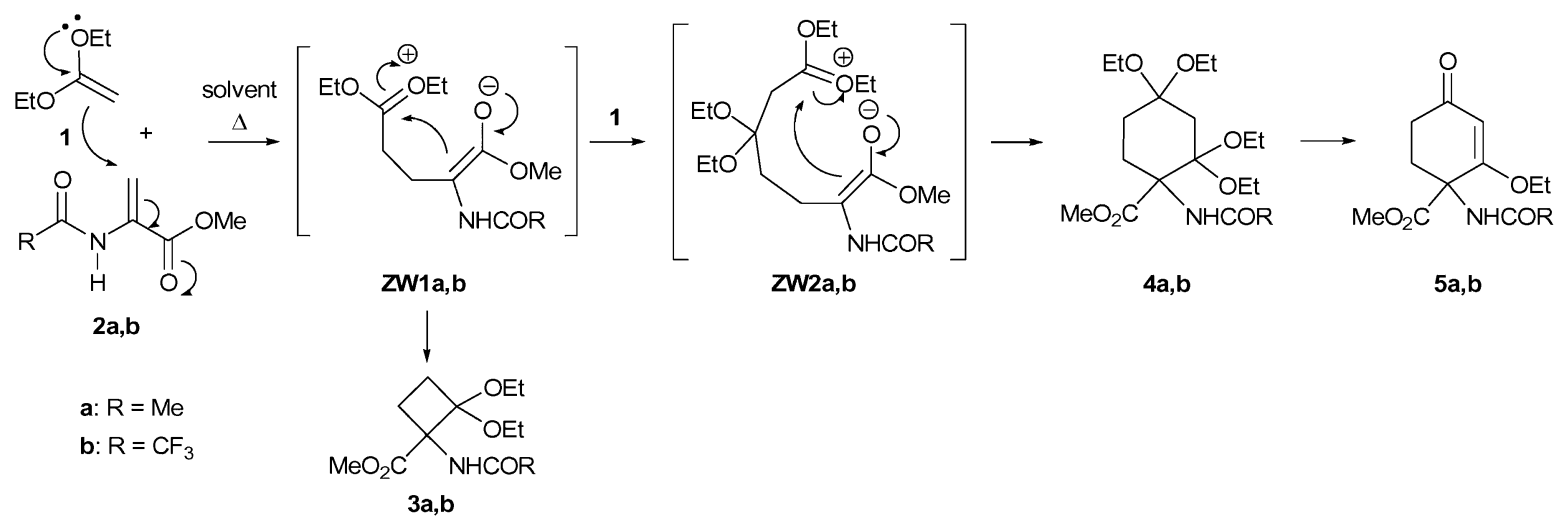

Scheme 1 Michael-Dieckmann type reactions of 2-acylaminoacrylates 2a,b with ketene diethyl acetal 1.

or their derivatives ${ }^{10}$ have been published, but there are very few that involve only olefins as the reactants. ${ }^{11-13}$

Simplification of the structure of ketene diethyl acetal 1 to ketene dimethyl acetal $\mathbf{1}^{\prime}$ was implemented in order to facilitate the calculations. Due to serious convergence problems in the gas phase, we had to include solvent effects into geometry optimizations in order to complete the whole pathways. We achieved this goal by using SCRF (self-consistent reaction field) methods. The minimum energy paths of the formal $[2+2]$ cycloadditions of $\mathbf{1}^{\prime}$ with olefins $\mathbf{2 a}$ and $\mathbf{2 b}$ could be fully calculated at the PCM/B3LYP/6-31+G(d) level and, as shown in Fig. 1 and Table 1, they involve a stepwise mechanism with two energy barriers (TS1 and TS2) connected by 1,4zwitterionic intermediates $\left(\mathrm{ZW1}^{\prime}\right)$. Two kinds of conformers were located for each transition structure and intermediate, namely anti and gauche. Although both the anti TS (transition structure(s)) and the anti intermediates are more stable than the gauche ones, the latter conformations were taken into account since they lead to the direct formation of cyclobutane products.

The most remarkable geometrical features of the TS and intermediates are shown in Fig. 2 and Fig. 3. Among them, it could be surprising that the $\mathrm{C}-\mathrm{C}$ bonds just formed are quite long (>1.6 $\AA$, corresponding to bond orders near to 0.8 ) in all

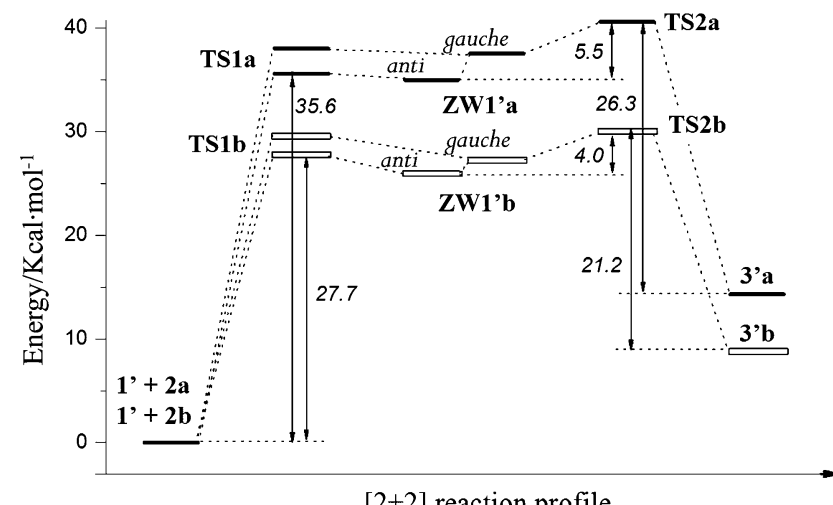

Fig. 1 Minimum energy paths in terms of $\Delta \Delta G$ along the [2+2] profile of olefins $\mathbf{2 a}$ (in black) and $\mathbf{2 b}$ (in white), calculated at the PCM/ B3LYP/6-31 + G(d) level. Numbers show the different activation barriers in $\mathrm{kcal} \mathrm{mol}^{-1}$ for each step of the cycloaddition.
$\mathrm{ZW} 1^{\prime}$ intermediates, which is, however, in accordance with those calculated by Bernardi et al. ${ }^{12}$ for similar structures. In general, the geometries of TS1 are close to those of the $\mathrm{ZW}^{\prime}$ intermediates, as expected for a late TS in an endergonic process.

Atoms in molecules (AIM) and natural bond orbital (NBO) atomic charge transfer analyses were carried out along the whole $[2+2]$ reaction profile for both olefins $\mathbf{2 a}$ and $\mathbf{2 b}$ at the PCM/B3LYP/6-31 + G(d) level (Fig. 4). These analyses show a progressive and significant development of negative charge in the ester region of the acceptor olefin moiety and of positive charge in the acetal region of the donor olefin moiety (see ESI for a more detailed definition $\ddagger$ ). Charge transfer reaches a maximum in the zwitterionic intermediate $\left(\mathrm{ZW1}^{\prime}\right)$ or the ring closing TS (TS2) and then decreases when the cyclobutane ring is formed. This study reveals the highly polar nature of the

Table 1 Calculated (B3LYP/6-31 $+\mathrm{G}(\mathrm{d}))$ relative electronic energies and Gibbs free energies (in kcal mol${ }^{-1}$ ) for the reacting species calculated in solution (acetonitrile with the Onsager model and PCM (polarized continuum model))

\begin{tabular}{|c|c|c|c|c|}
\hline & \multicolumn{2}{|c|}{ Onsager } & \multicolumn{2}{|l|}{ PCM } \\
\hline & $\Delta \Delta E$ & $\Delta \Delta G$ & $\Delta \Delta E$ & $\Delta \Delta G$ \\
\hline $\mathbf{1}^{\prime}+\mathbf{2 a}$ & 0.0 & 0.0 & 0.0 & 0.0 \\
\hline TSla anti & 17.9 & 32.6 & 20.3 & 35.6 \\
\hline TS1a gauche & 20.2 & 35.9 & 21.8 & 38.0 \\
\hline $\mathrm{ZW} 1^{\prime} \mathrm{a} a n t i$ & 18.4 & 33.8 & 19.3 & 35.0 \\
\hline ZW1'a gauche & 19.9 & 35.9 & 20.8 & 37.5 \\
\hline TS2a & 21.8 & 40.5 & 21.5 & 40.6 \\
\hline $\mathbf{3}^{\prime} \mathbf{a}$ & -6.7 & 12.6 & -5.3 & 14.3 \\
\hline $\operatorname{TS} 3 \mathrm{a}^{a}$ & 16.6 & 45.5 & - & - \\
\hline $\mathrm{ZW} 2^{\prime} \mathrm{a} a n t i^{a}$ & 4.9 & 36.6 & - & - \\
\hline $\mathbf{1}^{\prime}+\mathbf{2 b}$ & 0.0 & 0.0 & 0.0 & 0.0 \\
\hline TS1b anti & 12.9 & 23.5 & 16.2 & 27.7 \\
\hline TSlb gauche & 14.9 & 25.4 & 17.9 & 29.5 \\
\hline $\mathrm{ZW} 1^{\prime} \mathrm{b}$ anti & 8.2 & 19.7 & 13.7 & 25.9 \\
\hline ZW1'b gauche & 12.3 & 24.2 & 14.3 & 27.2 \\
\hline TS2b & 15.0 & 29.0 & 15.6 & 29.9 \\
\hline 3'b & -6.9 & 7.2 & -6.0 & 8.7 \\
\hline $\mathrm{TS} 3 \mathrm{~b}^{a}$ & 5.4 & 27.9 & - & - \\
\hline $\mathrm{ZW} 2^{\prime} \mathrm{b} a n t i^{a}$ & -3.4 & 21.2 & - & - \\
\hline
\end{tabular}

${ }^{a}$ The energy of an infinitely separated olefin $\mathbf{1}^{\prime}$ is added to the energy of TS1, ZW1' and TS2 to make the final relative energies comparable to those of TS3 and ZW2'. 


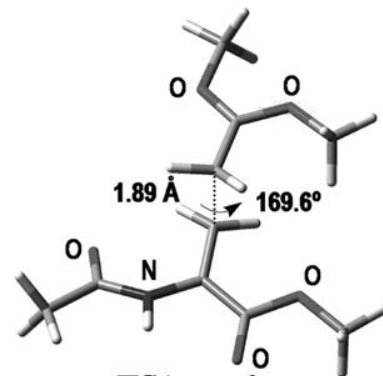

TS1 a anti

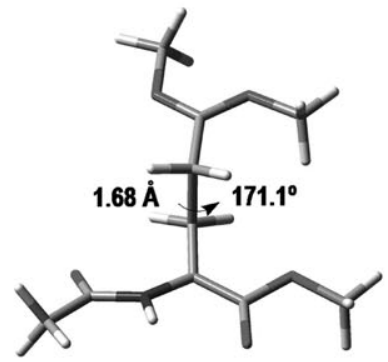

ZW1'a anti

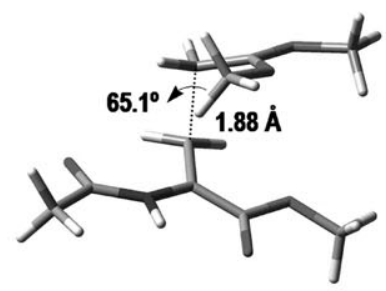

TS1a gauche

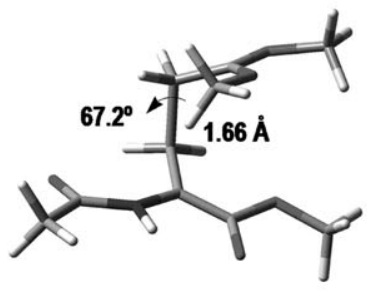

ZW1'a gauche

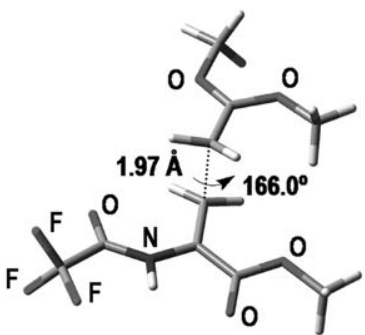

TS1b anti

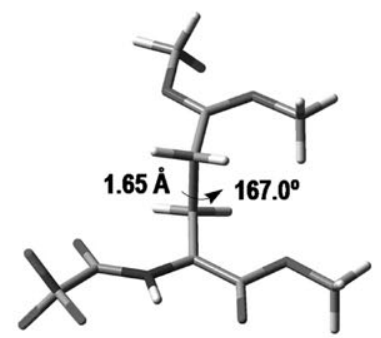

ZW1'b anti

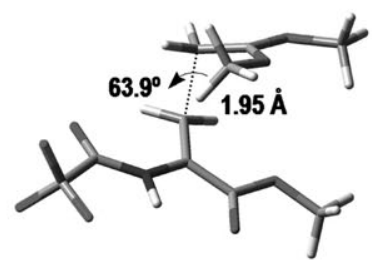

TS1b gauche

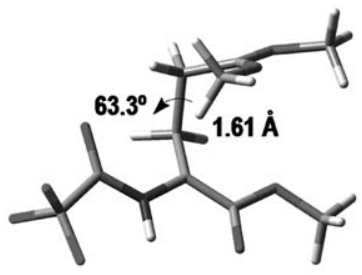

ZW1'b gauche

Fig. 2 TS1a,b and ZW1'a,b geometries of the Michael-Dieckmann type reaction leading to cyclobutanes, calculated at the PCM/B3LYP/ $6-31+\mathrm{G}(\mathrm{d})$ level.

calculated species and also supports the polar path proposed by other authors ${ }^{9,11}$ for this kind of thermal [2 +2$]$ cycloaddition.

Additionally, the calculations at the PCM/B3LYP/6$31+\mathrm{G}(\mathrm{d})$ level of the electrostatic potential (ESP) surfaces of $\mathrm{ZW1} 1^{\prime}$ reveal a high charge separation in the donor and acceptor olefin moieties, reinforcing again the highly polar character of these proposed 1,4-zwitterionic intermediates. It is important to note that the presence of the $\mathrm{CF}_{3}$ group results in a greater negative charge delocalization due to its strong inherent inductive effect. All these calculations are fully described in the ESI. $\ddagger$

The energy barriers from reactants to TS1 and from products $\mathbf{3}^{\prime}$ to TS2 are similar for both olefins $\mathbf{2 a}$ and $\mathbf{2 b}$ (Fig. 1) and these can be easily overcome at the reaction temperature - a situation that is consistent with the experimental evidence on the reversibility of this reaction, as outlined above.

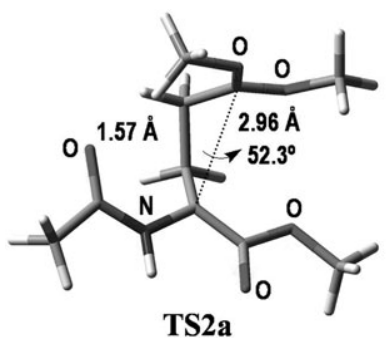

TS2a

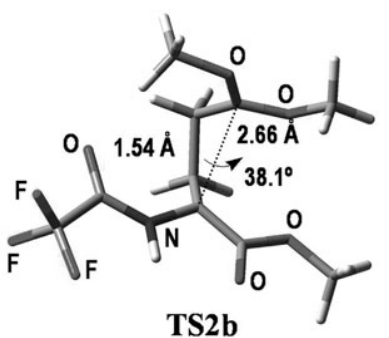

TS2b
Fig. 3 TS2a,b geometries of the Michael-Dieckmann type reaction leading to cyclobutanes, calculated at the PCM/B3LYP/6-31+G(d) level.
Much more significant, however, is the fact that the calculated activation barrier TS1b anti is $c a .7 .9 \mathrm{kcal} \mathrm{mol}^{-1}$ smaller than TS1a anti, indicating that olefin $\mathbf{2 b}$ presents a greater reactivity towards cycloaddition with olefin $\mathbf{1}^{\prime}$. This finding can be considered as the first indication that a second donor olefin $\mathbf{1}^{\prime}$ would be incorporated into $\mathrm{ZW1}^{\prime} \mathrm{b}$ anti more readily than into ZW1'a anti. To further test this hypothesis, the energy of the LUMO corresponding to the intermediates $\mathrm{ZW} 1^{\prime} \mathrm{a}$ anti $(-2.02 \mathrm{eV})$ and $\mathrm{ZW1}$ 'b anti $(-2.24 \mathrm{eV})$ were calculated at the PCM/B3LYP/6-31+G(d) level. A lower value was obtained for the latter and this is consistent with the greater reactivity of the acceptor olefin bearing the $\mathrm{CF}_{3}$ group.

We will now consider the second possibility for this reaction, namely the further addition of a second molecule of ketene dimethyl acetal $\mathbf{1}^{\prime}$ onto the zwitterionic intermediates. This addition leads to the formation of 1,6-zwitterionic hexamethylene intermediates (ZW2') which, in turn, will lead to the corresponding cyclohexane products (Scheme 1). Regarding the generation of $\mathrm{ZW} 2^{\prime}$ anti from $\mathrm{ZW} 1^{\prime}$ anti, the corresponding transition structures TS3 were found and characterized. These geometries could be calculated only at the Onsager/ B3LYP $/ 6-31+G(d)$ level, since we were unable to complete the optimizations of TS3 and ZW2' anti using the PCM method due to severe convergence problems (Fig. 5 and Table 1).

Very interestingly, TS3a is above TS2a by $5.0 \mathrm{kcal} \mathrm{mol}^{-1}$, indicating that for the acetamido-substituted olefin 2a the formal [2 +2$]$ cycloaddition to the cyclobutane product is kinetically favored (Fig. 5 and Table 1). This situation is in agreement with the experimental observations. In the case of the trifluoroacetamido-substituted counterpart, TS3b is 


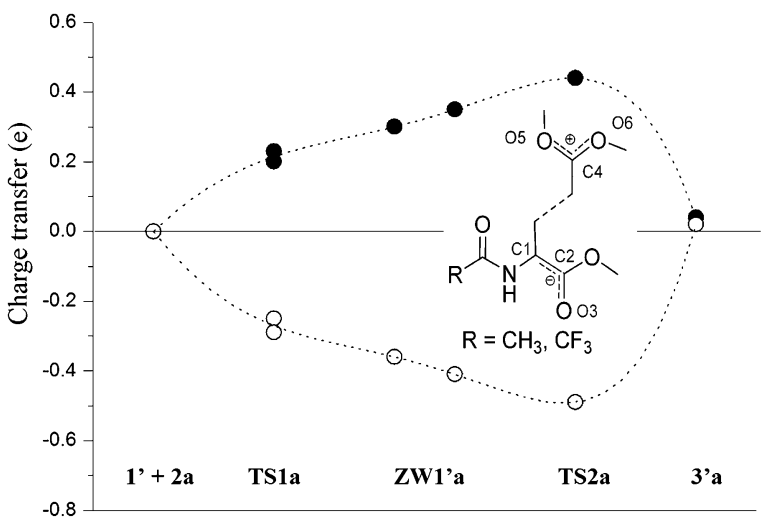

$[2+2]$ reaction profile

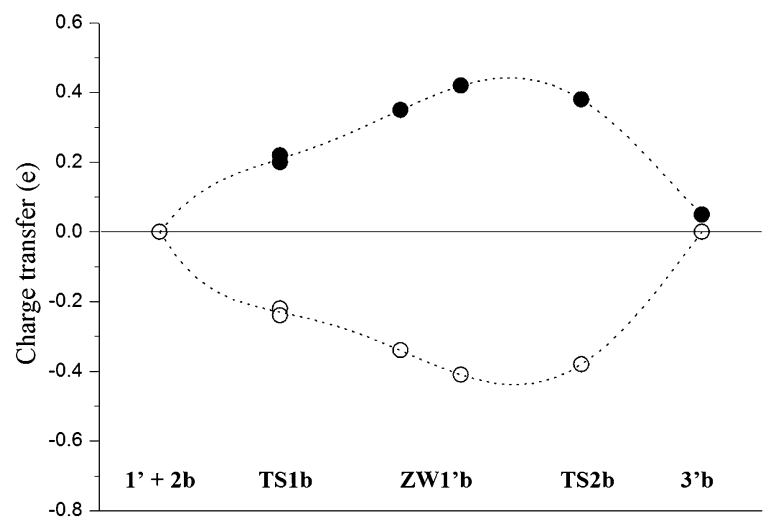

$[2+2]$ reaction profile

Fig. 4 AIM charge transfer along the $[2+2]$ reaction profile of olefins $2 \mathbf{a}$ (left) and $\mathbf{2 b}$ (right) calculated at the PCM/B3LYP/6-31 + G(d) level. The sums of the atomic charges at the acceptor olefin moiety $(\mathrm{C} 1-\mathrm{C} 2-\mathrm{O} 3)$ are represented with white circles $(\mathrm{O})$, and the sums of the atomic charges at the donor olefin moiety (O5-C4-O6) are represented with black circles (๑).

$1.1 \mathrm{kcal} \mathrm{mol}^{-1}$ below TS2b (Fig. 5 and Table 1), which agrees quite well with the chemoselectivity experimentally observed (exclusive formation of the cyclohexane product).

These energy values clearly indicate that this reaction pathway is much more favorable for $\mathbf{2 b}$ than for $\mathbf{2 a}$ - in line with the reactivity calculated for these olefins in the different reaction steps (Fig. 5 and Table 1). Attending to the Boltzmann distribution obtained from the aforementioned Gibbs free energies of all TS in Curtin-Hammett conditions, the change of a $\mathrm{CH}_{3}$ group to a $\mathrm{CF}_{3}$ group in the acceptor olefin alters the cyclobutane to cyclohexane ratio from $>99: 1$ to 10 : 90. This mechanistic scenario is supported by both the experimental and theoretical evidence described in this work.

\section{Conclusions}

The experimental and theoretical evidence presented in this work allow us to conclude that these Michael-Dieckmann type reactions of 2-acylaminoacrylates with ketene diethyl

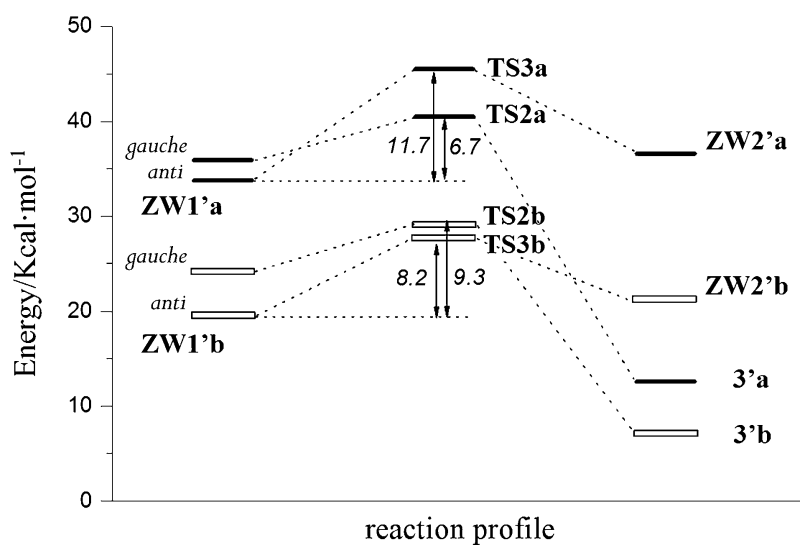

Fig. 5 Minimum energy paths in terms of $\Delta \Delta G$ along the second step profile of olefins $\mathbf{2 a}$ (in black) and $\mathbf{2 b}$ (in white), calculated at the Onsager/B3LYP/6-31 + G(d) level. Numbers show the different activation barriers in $\mathrm{kcal} \mathrm{mol}^{-1}$. Relative energies normalized according to values presented in Table 1 . acetal take place through a stepwise polar mechanism involving zwitterionic intermediates. An important modulation of the chemoselectivity of these reactions is observed depending on the nature of the acylamino group. Thus, in the case of the acetamido group, the $[2+2]$ cycloaddition leading to a cyclobutane product is preferred over the incorporation of a second molecule of ketene diethyl acetal. The insertion of the activating trifluoroacetamido group allows kinetic switching of the reactivity of 2-acylaminoacrylates towards the MichaelDieckmann type reaction with ketene diethyl acetal, leading exclusively to cyclohexane amino acid precursors in a very straightforward way and avoiding the use of Lewis acids. Investigations to extend this synthetic methodology to other reactions are currently in progress.

\section{Experimental}

\section{Synthesis}

General synthetic procedures. Melting points are uncorrected. All manipulations with air-sensitive reagents were carried out under a dry argon atmosphere using standard Schlenk techniques. Solvents were purified according to standard procedures. Analytical TLC was performed using Polychrom SI $\mathrm{F}_{254}$ plates. Column chromatography was performed using Kieselgel 60 (230-400 mesh). Organic solutions were dried over anhydrous $\mathrm{Na}_{2} \mathrm{SO}_{4}$ and, when necessary, concentrated under reduced pressure using a rotary evaporator. NMR spectra were recorded at $400 \mathrm{MHz}\left({ }^{1} \mathrm{H}\right)$ and at $100 \mathrm{MHz}\left({ }^{13} \mathrm{C}\right)$ and signals are reported in ppm downfield from TMS. Microanalyses were carried out on a CE Instruments EA-1110 analyser and were in good agreement with the calculated values.

2-Trifluoroacetamidoacrylic acid methyl ester (2b). Triethylamine $(10.8 \mathrm{~mL}, 77.6 \mathrm{mmol})$ and trifluoroacetic anhydride (6.9 mL, $48.4 \mathrm{mmol})$ were slowly added to a solution of serine methyl ester hydrochloride (3 $\mathrm{g}, 19.4 \mathrm{mmol}$ ) in $\mathrm{CH}_{2} \mathrm{Cl}_{2}$ $(50 \mathrm{~mL})$ at $0{ }^{\circ} \mathrm{C}$. The mixture was stirred for $24 \mathrm{~h}$, after which the solution was dark. Water $(40 \mathrm{~mL})$ was added, the phases 
were separated and the organic phase was washed with saturated $\mathrm{NaHCO}_{3}$. The organic layer was dried over anhydrous $\mathrm{Na}_{2} \mathrm{SO}_{4}$ and the solvent evaporated. The residue was purified by silica gel column chromatography, eluting with hexane-EtOAc $(8: 2)$, to give $2.7 \mathrm{~g}(70 \%)$ of 2-trifluoroacetamidoacrylic acid methyl ester $\mathbf{2 b}$ as a colorless oil. The spectroscopic data are in agreement with literature values. ${ }^{14}$

1-Acetamido-2,2-diethoxycyclobutane-1-carboxylic acid methyl ester (3a). The procedure has been described in the literature $^{3}$ for the case where tert-butyl alcohol was used as the solvent $(64 \%$ yield). For the other solvents the yields were as follows: cyclohexane $(2 \%)$, acetonitrile $(7 \%)$, toluene $(8 \%)$, dibutyl ether $(9 \%)$ and dichloroethane $(15 \%)$.

1-Trifluoroacetamido-2-ethoxy-4-oxocyclohex-2-ene-1-carboxylic acid methyl ester (5b). 2-Trifluoroacetamidoacrylic acid methyl ester $\mathbf{2 b}(100 \mathrm{mg}, 0.51 \mathrm{mmol})$ was dissolved in acetonitrile $(10 \mathrm{~mL})$ under an inert atmosphere and ketene diethyl acetal $1(0.14 \mathrm{~mL}, 1 \mathrm{mmol})$ was added. The mixture was warmed at $83{ }^{\circ} \mathrm{C}$ and a further solution of ketene diethyl acetal $(0.54 \mathrm{~mL}, 4 \mathrm{mmol})$ in acetonitrile $(5 \mathrm{~mL})$ was added using a syringe pump (45 min). The mixture was stirred for $48 \mathrm{~h}$ at this temperature, the solvent was evaporated and the crude product was purified by silica gel column chromatography, eluting with hexane-EtOAc $(6: 4)$, to yield $35 \mathrm{mg}(22 \%)$ of $\mathbf{5 b}$ as a white solid. $\mathrm{Mp}=100-102{ }^{\circ} \mathrm{C} .{ }^{1} \mathrm{H} \mathrm{NMR}\left(\mathrm{CDCl}_{3}\right): \delta$ 1.26-1.31 (m, 3H, $\left.\mathrm{OCH}_{2} \mathrm{CH}_{3}\right), 2.28-2.33\left(\mathrm{~m}, 1 \mathrm{H}, \mathrm{CH}_{2} \mathrm{C}\right)$, 2.52-2.56 (m, $\left.1 \mathrm{H}, \mathrm{CH}_{2} \mathrm{CO}\right), 2.60-2.69\left(\mathrm{~m}, 1 \mathrm{H}, \mathrm{CH}_{2} \mathrm{CO}\right)$, 2.80-2.96 (m, $\left.1 \mathrm{H}, \mathrm{CH}_{2} \mathrm{C}\right), 3.85-3.96\left(\mathrm{~m}, 5 \mathrm{H}, \mathrm{OCH}_{2} \mathrm{CH}_{3}\right.$, $\left.\mathrm{COOCH}_{3}\right), 5.58(\mathrm{~s}, 1 \mathrm{H}, \mathrm{CHC}), 7.58$ (br s, $\left.1 \mathrm{H}, \mathrm{NH}\right) \cdot{ }^{13} \mathrm{C}$ NMR $\left(\mathrm{CDCl}_{3}\right): \delta 13.6\left(\mathrm{OCH}_{2} \mathrm{CH}_{3}\right), 29.6\left(\mathrm{CH}_{2} \mathrm{C}\right), 33.4$ $\left(\mathrm{CH}_{2} \mathrm{CO}\right), 54.4\left(\mathrm{CH}_{3} \mathrm{CO}\right), 61.5(\mathrm{CNH}), 65.6\left(\mathrm{OCH}_{2} \mathrm{CH}_{3}\right)$, $106.4(C \mathrm{H}=\mathrm{C}), 115.2\left(\mathrm{q}, J=287 \mathrm{~Hz}, \mathrm{CF}_{3}\right), 155.8(\mathrm{q}, J=$ 38, $\left.\mathrm{COCF}_{3}\right), 167.8,169.5,196.6(\mathrm{CO})$. Anal. calcd for $\mathrm{C}_{12} \mathrm{H}_{14} \mathrm{NO}_{5} \mathrm{~F}_{3}$ : C, 46.61; H, 4.56; N, 4.53. Found: C, 46.48; $\mathrm{H}, 4.63 ; \mathrm{N}, 4.51 \%$. The same procedure was employed when tert-butyl alcohol was used as the solvent to obtain $\mathbf{5 b}$ in $14 \%$ yield. A temperature study $\left(-20{ }^{\circ} \mathrm{C}\right.$ to $\left.83{ }^{\circ} \mathrm{C}\right)$ was carried out when acetonitrile was used as a solvent, giving yields of $\mathbf{5 b}$ from $8 \%$ to $22 \%$.

\section{Computational details}

All calculations were carried out using the B3LYP hybrid functional $^{15}$ with the $6-31+\mathrm{G}(\mathrm{d})$ basis set. Full geometry optimizations and TS searches were carried out using the Gaussian 03 package. ${ }^{16}$ The possibility of different conformations was taken into account for all structures, although the discussion of the results is centered only on the most stable form in each case. Basis set superposition error (BSSE) corrections were not considered in this work. Frequency analyses were carried out at the same level used in the geometry optimizations, and the nature of the stationary points was determined in each case according to the appropriate number of negative eigenvalues of the Hessian matrix. Scaled frequencies were not considered since significant errors in the calculated thermodynamical properties are not found at this theoretical level. ${ }^{17}$ Where necessary, mass-weighted intrinsic reaction coordinate (IRC) calculations were carried out using the Gonzalez and Schlegel scheme ${ }^{18}$ in order to ensure that the TS were indeed connecting the appropriate reactants and products. Solvent effects were taken into account throughout this study using both the Onsager model ${ }^{19}$ and the polarized continuum model (PCM) ${ }^{20}$ as implemented in Gaussian 03. Given that strongly polarized reaction intermediates and transition states are expected for the reactions studied, solvent effects were included in the geometry optimization step unless otherwise stated. It is well-known that solvent effects may be able to change the position of the stationary points in the reaction coordinate, ${ }^{21}$ even leading to a change in the reaction mechanism. ${ }^{22}$ Unlike the Onsager model, in which the dielectric permittivity is the only parameter used to describe the solvent, the PCM model accounts for both the electrostatic and non-electrostatic components of the solvation energy, including dispersion and cavitation terms, through empirical parameters. In this study, we used the parameters internally stored in Gaussian 03 for acetonitrile because preliminary calculations confirmed that the electrostatic part of the solvation energy does not significantly change over a broad range of dielectric permittivities (for instance, changing from tert-butyl alcohol to acetonitrile). The solute molecular cavity was defined through the keyword UAHF, using a scaling factor defined by the keyword ALPHA $=1.40$.

Atoms in molecules (AIM) ${ }^{23}$ atomic charges were calculated by integrating the electron density $\rho(r)$ over the atomic basins with the PROMEGA algorithm implemented in the PROAIMV 94 rev. B program. ${ }^{24}$ This was done using the wave functions calculated with Gaussian 03 and the original Bader AIMPAC package. ${ }^{25} \mathrm{NBO}$ atomic charges and atomatom overlap-weighted NAO bond orders were calculated through a natural population analysis (NPA) ${ }^{26}$ and natural resonance theory (NRT), ${ }^{27}$ respectively, by means of the NBO $5 \mathrm{G}$ program $^{28}$ using upgraded Gaussian 03 as the interface.

\section{X-Ray analysis}

Crystal data for compound $\mathbf{5 b}: \mathrm{C}_{12} \mathrm{H}_{14} \mathrm{~F}_{3} \mathrm{NO}_{5}, M_{\mathrm{w}}=309.24$, colorless prism of $0.35 \times 0.30 \times 0.22 \mathrm{~mm}, T=173(2) \mathrm{K}$, triclinic, space group $P \overline{1}, Z=2, a=8.3685(2) \AA$, $b=9.1253(2) \AA, c=9.7248(3) \AA, \alpha=69.2894(10)^{\circ}, \beta=$ $82.1053(10)^{\circ}, \gamma=77.1832(14)^{\circ}, V=675.92(3) \AA^{3}, d_{\text {calc }}=$ $1.520 \mathrm{~g} \mathrm{~cm}^{-3}, F(000)=320, \lambda=0.71073 \AA$ (Mo K $\left.\alpha\right)$, $\mu=0.143 \mathrm{~mm}^{-1}$, Nonius kappa CCD diffractometer, $\theta$ range $=2.24-27.89^{\circ}, 9439$ collected reflections, 3169 unique $\left(R_{\mathrm{int}}=0.0338\right)$, full-matrix least-squares (SHELXL97), ${ }^{29}$ $R 1=0.0385, \mathrm{w} R 2=0.0900(I>2 \sigma(I)),(R 1=0.0542$, $\mathrm{w} R 2=0.0979$ all data), goodness of fit $=1.045$, residual electron density between 0.284 and -0.199 e $\AA^{-3}$. Hydrogen atoms were located from mixed methods (electron-density maps and theoretical positions). CCDC 294888. For crystallographic data in CIF or other electronic format see DOI: $10.1039 / \mathrm{b} 615220 \mathrm{a}$

\section{Acknowledgements}

We thank the Ministerio de Ciencia y Tecnología and FEDER (projects CTQ2005-06235/BQU, CTQ2005-08015, and CTQ2005-08016, and Ramon y Cajal contract of J. H. B.), the Universidad de La Rioja (project API-05/B01 and doctoral 
fellowship of G. J.-O.) and the Gobierno de La Rioja (project ANGI2005/01 and doctoral fellowships of N. C. and M. P.-F.).

\section{References}

1 (a) J. C. Namyslo and D. E. Kaufmann, Chem. Rev., 2003, 103, 1485; (b) E. Lee-Ruff and G. Mladenova, Chem. Rev., 2003, 103, 1449

2 (a) F. Avontins, Russ. Chem. Rev. (Engl. Transl.), 1993, 62, 897; (b) Y. Gaoni, Org. Prep. Proced. Int., 1995, 27, 185; (c) H. A. Bell, M. Y. Qureshi, R. J. Pryce, D. H. Janzen, P. Lemke and J. Clardy, J. Am. Chem. Soc., 1980, 102, 1409.

3 A. Avenoza, J. H. Busto, N. Canal and J. M. Peregrina, Chem. Commun., 2003, 1376.

4 (a) A. Avenoza, J. H. Busto, N. Canal and J. M. Peregrina, J. Org. Chem., 2005, 70, 330; (b) A. Avenoza, J. H. Busto, M. PérezFernández and J. M. Peregrina, Tetrahedron, 2005, 61, 4165; (c) A. Avenoza, J. H. Busto, N. Canal, J. M. Peregrina and M. PérezFernández, Org. Lett., 2005, 7, 3597; (d) A. Avenoza, J. H. Busto, N. Canal and J. M. Peregrina, Structural analysis of acetamidocyclobutanes by a combination of X-ray diffraction and NMR spectroscopy, in Structural Analysis of Cyclic Systems, ed. I. Iriepa, Research Signpost, Kerala, India, 2005, pp. 55-68; (e) G. JiménezOsés, F. Corzana, J. H. Busto, M. Pérez-Fernández, J. M. Peregrina and A. Avenoza, J. Org. Chem., 2006, 71, 1869.

5 K. Johnston, A. B. Padias, R. B. Bates and H. K. Hall, Jr, Langmuir, 2003, 19, 6416.

6 H. K. Hall, Jr, Angew. Chem., Int. Ed. Engl., 1983, 22, 440.

7 (a) R. Huisgen, Acc. Chem. Res., 1977, 10, 117; (b) H. Graf and R. Huisgen, J. Org. Chem., 1979, 44, 2594; (c) S. Nishida, I. Moritani and T. Teraji, J. Org. Chem., 1973, 38, 1878; (d) J. K. Williams, D. W. Wiley and B. C. McKusick, J. Am. Chem. Soc., 1962, 84, 2210.

8 (a) E. García-Expósito, M. J. Bearpark, R. M. Ortuño, M. A. Robb and V. Branchadell, J. Org. Chem., 2002, 67, 6070; (b) F. Bernardi, A. Bottoni, M. Olivucci, A. Venturini and M. A. Robb, J. Chem. Soc., Faraday Trans., 1994, 90, 1617; (c) S. Wilsey, L. González, M. A. Robb and K. N. Houk, J. Am. Chem. Soc., 2000, 122, 5866, and references cited therein.

9 (a) J. W. Scheeren, Recl. Trav. Chim. Pays-Bas, 1986, 105, 71; (b) R. Huisgen, Pure Appl. Chem., 1980, 52, 2283.

10 (a) U. Salzner and S. M. Bachrach, J. Org. Chem., 1996, 61, 237; (b) E. T. Seidl and H. F. Schaefer III, J. Am. Chem. Soc., 1991, 113, 5195; (c) L. J. Schaad, I. Gutman, B. A. Hess, Jr and J. Hu, J. Am. Chem. Soc., 1991, 113, 5200; (d) B. Lecea, A. Arrieta, I. Arrastia and F. P. Cossío, J. Org. Chem., 1998, 63, 5216; (e) J.-M. Pons, M. Oblin, A. Pommier, M. Rajzmann and D. Liotard, J. Am. Chem. Soc., 1997, 119, 3333; ( $f$ ) C. Zhou and D. M. Birney, J. Am. Chem. Soc., 2002, 124, 4231; $(g)$ R. López, D. Suárez, T. L. Sordo and M. F. Ruiz-López, Chem.-Eur. J., 1998, 4, 328; (h) M. Alajarín, A. Vidal, F. Tovar, A. Arrieta, B. Lecea and F. P. Cossío, Chem.-Eur. J., 1999, 5, 1106; (i) T. N. Truong, J. Phys. Chem. B, 1998, 102, 7877; (j) D. A. Singleton, Y. Wang, H. W. Yang and D. Romo, Angew. Chem., Int. Ed., 2002, 41, 1572; (k) F. Bernardi, A. Bottoni, M. A. Robb and A. Venturini, J. Am. Chem. Soc., 1990, 112, 2106; (l) A. Venturini and J. González, J. Org. Chem., 2002, 67, 9089.

11 D. Lim and W. L. Jorgensen, J. Phys. Chem., 1996, 100, 17490.

12 (a) F. Bernardi, R. R. Pappalardo, M. A. Robb and A. Venturini, J. Mol. Struct. (THEOCHEM), 1995, 357, 33; (b) F. Bernardi, A. Bottoni, M. A. Robb, H. B. Schlegel and G. Tonachini, J. Am. Chem. Soc., 1985, 107, 2260.
13 S. Yamazaki, H. Fujitsuka and S. Yamabe, J. Org. Chem., 1992, 57, 5610.

14 C. C. Duke, J. K. Macleod, R. E. Summons, D. S. Letham and C. W. Parker, Aust. J. Chem., 1978, 31, 1291.

15 (a) C. Lee, W. Yang and R. Parr, Phys. Rev. B: Condens. Matter Mater. Phys., 1988, 37, 785; (b) A. D. Becke, J. Chem. Phys., 1993, 98, 5648.

16 M. J. Frisch, G. W. Trucks, H. B. Schlegel, G. E. Scuseria, M. A. Robb, J. R. Cheeseman, J. A. Montgomery, Jr., T. Vreven, K. N. Kudin, J. C. Burant, J. M. Millam, S. S. Iyengar, J. Tomasi, V. Barone, B. Mennucci, M. Cossi, G. Scalmani, N. Rega, G. A. Petersson, H. Nakatsuji, M. Hada, M. Ehara, K. Toyota, R. Fukuda, J. Hasegawa, M. Ishida, T. Nakajima, Y. Honda, O. Kitao, H. Nakai, M. Klene, X. Li, J. E. Knox, H. P. Hratchian, J. B. Cross, V. Bakken, C. Adamo, J. Jaramillo, R. Gomperts, R. E. Stratmann, O. Yazyev, A. J. Austin, R. Cammi, C. Pomelli, J. Ochterski, P. Y. Ayala, K. Morokuma, G. A. Voth, P. Salvador, J. J. Dannenberg, V. G. Zakrzewski, S. Dapprich, A. D. Daniels, M. C. Strain, O. Farkas, D. K. Malick, A. D. Rabuck, K. Raghavachari, J. B. Foresman, J. V. Ortiz, Q. Cui, A. G. Baboul, S. Clifford, J. Cioslowski, B. B. Stefanov, G. Liu, A. Liashenko, P. Piskorz, I. Komaromi, R. L. Martin, D. J. Fox, T. Keith, M. A. Al-Laham, C. Y. Peng, A. Nanayakkara, M. Challacombe, P. M. W. Gill, B. G. Johnson, W. Chen, M. W. Wong, C. Gonzalez and J. A. Pople, GAUSSIAN 03 (Revision B.05), Gaussian, Inc., Wallingford, CT, 2004.

17 C. W. Bauschlicher, Jr, Chem. Phys. Lett., 1995, 246, 40.

18 (a) C. Gonzalez and H. B. Schlegel, J. Chem. Phys., 1989, 90, 2154; (b) C. Gonzalez and H. B. Schlegel, J. Phys. Chem., 1990, 94, 5523.

19 (a) L. Onsager, J. Am. Chem. Soc., 1936, 58, 1486; (b) M. W. Wong, K. B. Wiberg and M. J. Frisch, J. Am. Chem. Soc., 1992, 114, 1645, and references cited therein.

20 (a) M. Cossi, V. Barone, B. Mennucci and J. Tomasi, Chem. Phys. Lett., 1998, 286, 253; (b) J. Tomasi, B. Mennucci and E. Cancès, J. Mol. Struct. (THEOCHEM), 1999, 464, 211; (c) M. Cossi, G. Scalmani, N. Rega and V. Barone, J. Chem. Phys., 2002, 117, 43, and references cited therein.

21 (a) M. F. Ruiz-López, X. Assfeld, J. I. García, J. A. Mayoral and L. Salvatella, J. Am. Chem. Soc., 1993, 115, 8780; (b) X. Assfeld, M. F. Ruiz-López, J. I. García, J. A. Mayoral and L. Salvatella, J. Chem. Soc., Chem. Commun., 1995, 1371.

22 See for instance: J. I. García and E. Humeres, J. Org. Chem., 2002, 67, 2755.

23 R. F. W. Bader, Atoms in Molecules - A Quantum Theory, Oxford University Press, Oxford, 1990.

24 F. W. Biegler-König, R. F. W. Bader and T.-H. Tang, J. Comput. Chem., 1982, 3, 317.

25 R. F. W. Bader, AIMPAC, McMaster University, Hamilton. ON L8S 4M1, Canada, see http://www.chemistry.mcmaster.ca/aimpac/.

26 (a) A. E. Reed and F. Weinhold, J. Chem. Phys., 1983, 78, 4066; (b) A. E. Reed, R. B. Weinstock and F. Weinhold, J. Chem. Phys., $1985, \mathbf{8 3}, 735$

27 E. D. Glendening and F. Weinhold, J. Comput. Chem., 1998, 19, 610.

28 E. D. Glendening, J. K. Badenhoop, A. E. Reed, J. E. Carpenter, J. A. Bohmann, C. M. Morales and F. Weinhold, NBO 5.0, Theoretical Chemistry Institute, University of Wisconsin, Madison, USA, 2001.

29 G. M. Sheldrick, SHELXL-97, Program for refinement of crystal structures, University of Göttingen, Germany, 1997. 